\title{
Right place. Right time. Right tool: guidance for using target analysis to increase the likelihood of invasive species detection
}

\author{
Jeffrey T. Morisette (D) J Jamie K. Reaser $(\mathbb{D} \cdot$ Gericke L. Cook • Kathryn M. Irvine • \\ Helen E. Roy
}

Received: 3 November 2019/ Accepted: 3 November 2019/Published online: 22 November 2019

(C) The Author(s) 2019

\begin{abstract}
In response to the National Invasive Species Council's 2016-2018 Management Plan, this paper provides guidance on applying target analysis as part of a comprehensive framework for the early detection of and rapid response to invasive species (EDRR). Target analysis is a strategic approach for detecting one or more invasive species at a specific locality and time, using a particular method and/or technology(ies). Target analyses, which are employed across a wide range of disciplines, are intended to increase the likelihood of detection of a known target
\end{abstract}

J. T. Morisette $(\bowtie)$

National Invasive Species Council Secretariat c/o

National Park Service, 1201 Oakridge Drive, Fort Collins,

CO 80525, USA

e-mail: jeffrey_morisette@ios.doi.gov

J. K. Reaser

Center for Large Landscape Conservation, $303 \mathrm{~W}$

Mendenhall St \#4, Bozeman, MT 59715, USA

G. L. Cook

US Department of Agriculture, Animal and Plant Health Inspection Service, 2150 Centre Ave, Building B,

Fort Collins, CO 80526, USA

K. M. Irvine

US Geological Survey, Northern Rocky Mountain Science Center, 2327 University Way, Suite 2, Bozeman, MT 59715, USA

H. E. Roy

UK Centre for Ecology and Hydrology, Wallingford,

Oxfordshire, UK in order to maximize survey effectiveness and costefficiency. Although target analyses are not yet a standard approach to invasive species management, some federal agencies are employing target analyses in principle and/or in part to improve EDRR capacities. These initiatives can provide a foundation for a more standardized and comprehensive approach to target analyses. Guidance is provided for improving computational information. Federal agencies and their partners would benefit from a concerted effort to collect the information necessary to perform rigorous target analyses and make it available through open access platforms.

Keywords Detection - Early detection and rapid response (EDRR) - Invasive species · Target analysis

\section{Introduction}

An invasive species is, "with regard to a particular ecosystem, a non-native organism whose introduction causes or is likely to cause economic or environmental harm, or harm to human, animal, or plant health" (Executive Office of the President 2016). The early detection of and rapid response to invasive species (EDRR) is a guiding principle for addressing invasive species in an effective and cost-efficient manner (Reaser et al. 2019a). In order to detect invasive species early in the invasion process, surveyors 
(including inspectors at points of entry and field-based personnel) need to know the characteristics of the species of interest and be in the right place, at the right time, and with the right tool(s). If these criteria are not met, invasive species may bypass prevention measures, establish, spread, and cause adverse impacts to valued assets.

The 2016-2018 National Invasive Species Council (NISC) Management Plan calls for an assessment of the capacity of federal inventory and monitoring programs to detect invasive species (NISC 2016). Reaser et al. (2019a) provide a general overview of the assessment findings and identify capacity building needs. In this complementary paper, we provide guidance for using target analysis as a tool to maximize the likelihood of invasive species detection through inventory and monitoring programs (collectively referred to as surveillance herein). We define target analysis as a strategic approach for detecting one or more invasive species at a specific locality and time, using a particular method and/or technology(ies). Target analysis is a key component of a holistic EDRR framework, as described by Reaser et al. (2019a, b, c).

Invasive species can be detected incidentally through opportunistic identification (Morrisseau and Voyer 2014) such as citizen science programs (Waugh 2009). However, the implementation of proactive prevention measures, including surveillance, is considered the most cost-effective approach to addressing invasive species (Lodge et al. 2006; Leung et al. 2002; McNeely et al. 2001). By enabling the development of robust and efficient statistical sampling designs, target analyses can maximize the effectiveness and costefficiency of invasive species detection when the target is known (i.e., a decision has been made to survey for specific invasive species) (Chin et al. 2018; Berec et al. 2015; Hoffman et al. 2016; Wang et al. 2014; US Forest Service n.d.; http://www. landscapetoolbox.org, accessed 24 September 2018). Target analysis is particularly advantageous for "finding the needle in the haystack" when the target is (1) a high risk to valued assets if it goes undetected, (2) mobile, (3) self-perpetuating, (4) rare (e.g., introduced population size is small), (5) a novel species that can have unpredictable behavior (such as dispersal or competition), and (6) subject to response measures that are substantially constrained with respect to time, funding, and other resources.
Target analysis, in various forms, is applied across a wide range of technical fields where the criteria listed above are applicable. Examples include sampling design and theory, particularly for high-risk contexts (De Gruijter et al. 2006); probabilistic risk analysis in bioterrorism (Ezell and Winterfeldt 2009); pandemic prediction surveillance and modeling (Watters and Biernacki 1989); and wildfire management (Schroeder et al. 2016; Khamukhin and Bertoldo 2016). Lessons learned from the use of target analysis components within these contexts could help advance invasive species applications.

Taleb (2007) regards rarity, extreme impact, and retrospective predictability as attributes of a "Black Swan," a theory he developed to explain the disproportional role of high-profile, hard-to-predict, rare events in human history. Related to the Black Swan concept, Lindenmayer et al. (2010) describe "ecological surprises" as events beyond either expected or unexpected results. Because the management of established and potential invasive species constitutes planning in light of uncertainty (Cook et al. 2014), applying target analyses to invasive species management may also benefit from applying event-prediction theory and associated models. For example, the arrival of invasive dreissenid mussels in Lake Powell (Colorado) and Lake Mead (Nevada/Arizona) is a Black Swan scenario. Although we now know that invasive mussels can thrive throughout the western US (Wong and Gerstenberger 2015), previous guidance (which had gone through rigorous peer review) on where to monitor for mussel introductions indicated very little to no risk in areas that later became heavily invaded (Drake and Bossenbroek 2004). This was an "ecological surprise" (Lindenmayer et al. 2010). Given the uncertainties inherent to any biological model, practitioners need to apply new information as it becomes available to better inform both iterative modeling and adaptive management decisions. This principle is reflected in arrows indicating information iteration in Fig. 1.

Drawing from the aforementioned fields of application, we regard target analyses as meta-analyses that integrate raw data, as well as information generated for and from other analytical components of a comprehensive EDRR system. Figure 1 depicts target analysis as generating information on when, where, and how to look for a given species or set of species based on the evaluation of key information inputs. It 
Fig. 1 Target analysis: a conceptual framework. The figure depicts the input parameters, analytical approaches, and results (output) that can be used to guide a sampling strategy for specific species or groups of species in order to maximize the likelihood of their detection. Input data quantitatively characterize the biology and ecology of the target species, its distribution and movement patterns, as well as the methods and technologies used to detect the species in a context similar to the recipient ecosystem(s) of concern. The data analysis includes computations that use robust statistical sample survey design, modeling to forecast in space and time, and mapping to provide a spatial-temporal representation of locations for strategic sampling

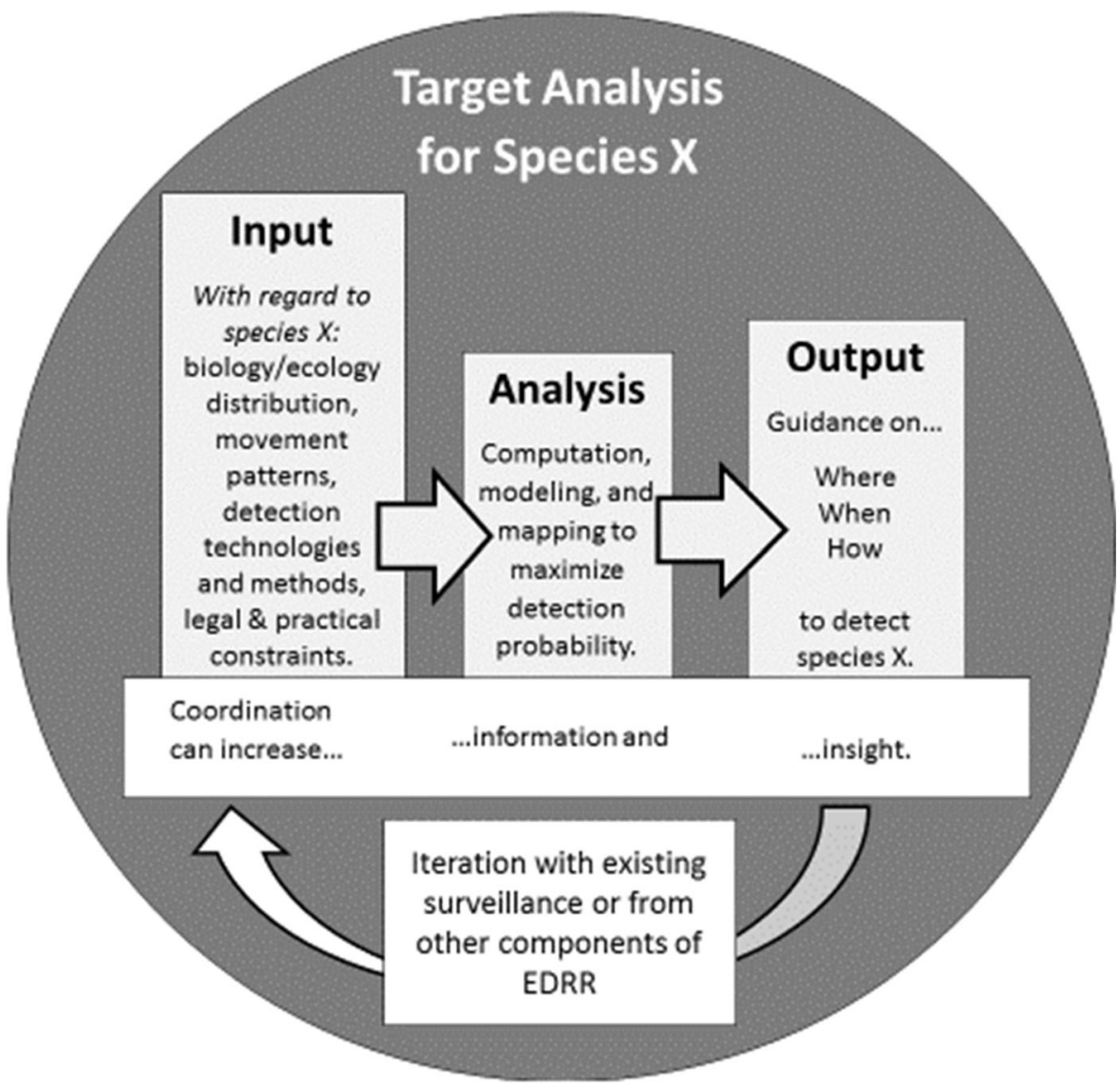

provides a conceptual framework for target analysis, depicting the input parameters, analytical approaches, and results (output) that can be used to guide a sampling strategy for specific invasive species or groups of invasive species in order to maximize the likelihood of detection. The essence of target analysis is to use the best available information, integrated through computation, modeling, and mapping to answer key questions pertaining to when, where, and how to most effectively and cost-efficiently detect invasive species. The data inputs must be as reliable (authoritatively verified) and as up-to-date as possible.

Currently, no standardized approach to target analysis exists. Those conducting target analyses optimally use the most robust analytical approaches and tools available to them and report their methods. Russell et al. (2017) provide a practical example of target analysis computations. They consider the characteristics of the species of interest, multiple devices/ technique being used, and the time frame to optimize surveillance for invasive rodents on islands after an eradication has been attempted. Although they do not include spatial variables in their formula, they do recognize the importance of spatial considerations by noting that the parameters in their calculations will differ between sites and in different climates.

The computations that constitute target analysis are largely built on existing information and use statistical sampling theory (Russell et al. 2017; Berec et al. 2015; Hoffman et al. 2016; US Forest Service n.d.; http:// www.landscapetoolbox.org, accessed 24 September 2018). Modeling helps extend estimates about the invasive species in space and/or time (Cook et al. 2019; Wang et al. 2014). Mapping is used to consider important geospatial information, jurisdictional boundaries, and logistical aspects of surveillance strategy. In addition to highlighting the flow of input, analysis, and output, Fig. 1 also emphasizes coordination and iteration for conducting target analysis.

The following are questions to consider when one conducts a target analysis. These questions are intended to help identify the data to be processed 
through computational, mapping, and/or modeling approaches available to the analyst. For regulated species, analytical approaches must be consistent with the directives of relevant legal frameworks (BurgosRodríguez and Burgiel 2019).

Where?

1. What habitat(s) does the species occupy in its native range?

2. What resources (food, shelter, reproductive sites, etc.) is it attracted to?

3. What conditions and features (natural and humanconstructed) promote or deter the invasive species?

4. How does the species spread by its own volition and in what territory/range size?

5. How can the species be transported, and what are the patterns associated with this mode of transport (i.e., what are the known, existing, or potential pathways)?

6. What are the most feasible interception points along this pathway?

7. How do 1-6 change through time (see When list)?

When?

1. What are the daily activity patterns of the species (diurnal, nocturnal, crepuscular)?

2. What are the weather-associated activity patterns for the species (temperature, moisture, etc.)?

3. What are the activity patterns of the species with regard to patterns in the availability of food, shelter, and other resources?

4. What are the activity patterns of the species with regard to the presence or absence of other species (predators, competitors, parasites, etc.)?

5. What are the seasonal activity patterns of the species (phenology, migratory patterns, population periodicity over years, etc.)?

6. When are the species most prevalent or likely to occur at the various steps of the invasion pathway?

How?

1. What visual, auditory, or other characteristics of the species facilitate detection?

2. What detection methods have been effective/ ineffective in similar contexts?
3. What detection technologies have been effective/ ineffective in similar contexts?

4. What are the most feasible detection points along the pathway?

5. How do the above (1-5) change according to time and location (see Where and When lists)?

6. How do authorities, policies, feasibility, and cost effectiveness influence application of the above $(1-5)$ ?

Federal agencies employing target analysis for invasive species EDRR, whether in name or principle, are largely doing so to increase detection rates at points of entry (pathway interception) and/or in known, potentially recipient ecosystems. In the points-of-entry context, special considerations for target analysis include (1) regulatory and policy directives that could influence method options, such as the Security and Accountability for Every Port Act (2006) and the US Department of Agriculture's (USDA) Agricultural Quarantine Inspection Monitoring program (USDA 2011) (see also Burgos-Rodríguez and Burgiel 2019); (2) the high volume of a wide diversity of conveyances and containers that could be moving invasive species as commodities or hitchhikers; (3) the dynamic nature of trade and travel patterns (Haack et al. 2014); (4) the advantage (over the broader spatial domain of recipient ecosystems) of very specific, known locations from which to monitor (US Department of Homeland Security and USDA 2003); and (5) the ability to include reliable information on the type, source, and movement history of the potential conveyance (e.g., baggage, cargo, trailered watercraft; USDA 2011). With regard to recipient ecosystems, special considerations for target analysis include the need to understand (1) pathway patterns and trends (i.e., how invasive species are entering and moving through the ecosystem) (USDA 2018); (2) how ecosystem characteristics vary over time and space; and (3) how species traits relate to these ecological patterns and trends (Brooks and Klinger 2012; Stohlgren and Schnase 2006).

To the best of our knowledge, no federal agency is explicitly conducting comprehensive target analysis for invasive species, and there is no overarching federal focus on target analysis as part of an invasive species EDRR framework. However, several agencies use components of target analysis and analytical approaches to develop invasive species sampling 
strategies. These could be considered target analyses in concept, or aspects of target analyses. We provide five examples below:

Department of Homeland Security The National Agriculture Cargo Targeting Unit (NACTU) is an operational arm of the Agriculture Programs and Trade Liaison (APTL) co-located at the National Targeting Center. Under the Department of Homeland Security, US Customs and Border Protection (CBP) Office of Field Operation, APTL has established NACTU to improved CBP's agriculture quarantine targeting through multiple pathways to include cargo and passengers. NACTU operations analyze national quarantine activities and apply resulting trends to importation practices in multiple pathways in order to identify quarantine risks before they arrive. With a strong focus on pest exclusion and trade, NACTU identifies inconsistencies in importation trends and applies risk-based criteria to identify repeat violators and high-risk pathways. This makes agriculture exams more efficient, thereby acting as a force multiplier towards CBP's agriculture mission.

Department of Agriculture On an annual basis, USDA's Animal and Plant Health Inspection Service (APHIS) has been using aspects of target analyses to forecast the likelihood of detecting European gypsy moth (Lymantria dispar dispar) outside of the existing federal quarantine area. Because pathways for spread differ across space (from natural spread over relatively short distances to human-assisted spread over long distances), the gypsy moth model is regionalized to capture these different pathways (Cook et al. 2019). The resulting model output is used to guide sampling, directing more effort to high-probability locations (USDA 2014). Using measurements of heat accumulation (such as growing degree days) in phenology models that predict the emergence of the adult flying stage, APHIS targets trap placement for optimal pest detection across space and time (Sheehan 1992; Régnière and Nealis 2002).

Department of the Interior The US Geological Survey (USGS) is considering a target analysis approach to enhance detection of the invasive fungus (Pseudogymnoascus destructans; Pd) that is commonly known to cause white-nose syndrome when infecting bats (Jachowski et al. 2014; Rodhouse et al. 2012). The analytical approach leverages monitoring data to project the likelihood of at-risk bat species occurrence at unsurveyed locations and to inform the timing of capturing bats in order to increase the chances of detecting Pd on susceptible bats.

The US National Park Service (NPS) has an extensive biodiversity inventory and monitoring program (Fancy et al. 2009). Invasive plant surveys and response are coordinated through their Exotic Plant Management Team (EPMTs). The Mid-Atlantic Inventory and Monitoring Network established a single platform where resource managers and support staff could access baseline information on natural resource inventory and monitoring, as well as information on observations and management actions from the EPMT and fire management staff (Dammeyer and Shedd 2017). The system can improve surveillance by providing documentation and maps of what has already been detected and treated as well as baseline ecological and disturbance information that can help inform future surveillance.

Inter-agency Together, the US Environmental Protection Agency (EPA) and US Fish and Wildlife Service (USFWS) are working with state agencies to evaluate approaches to the early detection of aquatic invasive species with the intent of establishing survey protocols and designing a process for routine evaluation of survey performance (Hoffman et al. 2016).

These exemplary programs can serve as a foundation on which to build a more holistic approach to target analysis within the US federal government and elsewhere. Agencies with responsibilities for invasive species detection could benefit from a standard approach to surveillance (intercept) data management and target analysis protocols. In keeping with the tenets of adaptive management (Buckley 2008), this would enable target analyses to be refined over time. By comparing targeted detections against baseline expectations, surveyors can determine if they are appropriately targeting the selected samples (Jarrad et al. 2015). The outcome of these analyses can be used to improve the quality of the target analysis and better optimize detection strategies (Hulme 2009). Artificial intelligence (machine learning) could also be used to identify detection patterns and trends and "train" target analyses to become more sophisticated for certain contexts and species (see Martinez et al. 2019).

Overall, the capacity for conducting target analyses can be improved through advancements in the quantity and quality of the information required for the analyses. In particular, this includes 
1. Improvements in collection of and access to nonnative species occurrence data (Reaser et al. 2019c),

2. Increasing our knowledge of species biology and ecology (Reaser et al. 2019b; Meyers et al. 2019),

3. Advances in invasive species detection technologies and data on their efficacy (Martinez et al. 2019; Kamenova et al. 2017; Lodge et al. 2006),

4. Standardization and expansion of other decision support tools, such as risk screening (Meyers et al. 2019), horizon scanning for strategic planning (Roy et al. 2015; Sutherland and Woodroof 2009), and dashboards for operational reporting [e.g., from business (Eckerson 2010) or human health contexts (Kunjan et al. 2018)] and

5. Increased awareness, communication, and coordination across agencies and with other monitoring programs [e.g., citizen science (Kamenova et al. 2017; Tulloch et al. 2013; Roy et al. 2012)].

\section{Conclusion}

Executive Orders 13112 (Executive Office of the President 1999) and 13751 (Executive Office of the President 2016) charge federal agencies with taking a cooperative, cost-efficient approach to addressing invasive species. They underscore the need to apply the best-available data, analytical models, and technologies to support decision-making. Target analysis is an underused, yet vital tool for preventing the introduction and spread of invasive species. The broader application of target analysis could improve collaboration in species surveillance (especially across jurisdictions), information sharing, analytical tool development, and technology advancement.

The guidance provided here is not meant to be prescriptive or comprehensive; it provides a starting point for advancing the development and application of target analysis for invasive species EDRR with a view towards more integrated and comprehensive EDDR efforts. Federal agencies and their partners would benefit from greater awareness of target analysis as addressed in theory and by other fields of practice. This could include an assessment of opportunities for strengthening and expanding use of target analysis within their EDRR programs (e.g., watercraft inspection stations), a concerted effort to expand target analysis application where needed/warranted, ongoing improvements in the quantity and quality of information drawn upon for target analyses, and the communication of target analysis reports into an open-access clearinghouse for future reference. Collectively, these efforts could help increase early detection while maximizing the efficiency of existing or future invasive species surveillance efforts.

Acknowledgements This paper advances action 5.1.7 of the 2016-2018 NISC Management Plan. The authors are grateful to everyone who contributed to the federal agency surveys and supplemental inquiries. We thank the following individuals for their comments and insights: Menwyelet Atsedu, John Sagle, Nidhi Singla, Terri Hogan, Matthew Schmitt, Craig Young, Sarah Veatch, and Jhoset A. Burgos-Rodríguez. Thanks to the following reviewers for an array of useful comments and suggestions: Paul Chaloux, Russ Bulluck, Theresa Boyle, and Dana Cole, USDA; Amy Yackel-Adams and Geneva Chong, USGS; Jim Comiskey, NPS; and Michael Hoff, USFWS (retired). Special thanks to Jason Kirkey for his editorial assistance. Financial support for this project was provided through Service First funding to the NISC Secretariat, as well as the intramural research program of the US Department of Agriculture, Animal and Plant Health Inspection Service. The findings and conclusions in this article are those of the author(s); they do not necessarily represent the views of the NISC Secretariat, have not been formally disseminated by the US Department of Agriculture, and should not be construed to represent any agency determination or policy. The majority of Jamie K. Reaser's contributions occurred while Executive Director of the National Invasive Species Council.

Open Access This article is distributed under the terms of the Creative Commons Attribution 4.0 International License (http:// creativecommons.org/licenses/by/4.0/), which permits unrestricted use, distribution, and reproduction in any medium, provided you give appropriate credit to the original author(s) and the source, provide a link to the Creative Commons license, and indicate if changes were made.

\section{References}

Berec L, Kean JM, Epanchin-Niell R, Liebhold AM, Haight RG (2015) Designing efficient surveys: spatial arrangement of sample points for detection of invasive species. Biol Invasions 17(1):445-459

Brooks ML, Klinger R (2012) Prioritizing species and sites for early-detection programs. In: Welch BA, Geissler PH and Latham, P (eds) Early detection of invasive plants-principles and practices. US Geological Survey Scientific Investigations Report 2012-5162, Washington, DC

Buckley YM (2008) The role of research for integrated management of invasive species, invaded landscapes and communities. J Appl Ecol 45(2):397-402 
Burgos-Rodríguez J, Burgiel SW (2019) Federal legal authorities for the early detection of and rapid response to invasive species. Biol Invasions. https://doi.org/10.1007/s10530019-02148-w

Chin J, Gao G, Schloemann R, Sharan S (2018) Building resilience to the economic threat of invasive species. Swiss Re Institute, Zurich

Convention on Biological Diversity (2014) Pathways of introduction of invasive species, their prioritization and management. https://www.cbd.int/doc/meetings/sbstta/sbstta18/official/sbstta-18-09-add1-en.pdf. Accessed 22 Aug 2018

Cook CN, Inayatullah S, Burgman MA, Sutherland WJ, Wintle BA (2014) Strategic foresight: how planning for the unpredictable can improve environmental decision-making. Trends Ecol Evol 29(9):531-541

Cook G, Jarnevich C, Warden M, Downing M, Withrow J, Leinwand I (2019) Iterative models for early detection of invasive species across spread pathways. Forests 10:108

Dammeyer N, Shedd J (2017) Integrating science into resource management via web GIS. Geospatial Insights 2(5):2

De Gruijter J, Brus DJ, Bierkens MF, Knotters M (2006) Sampling for natural resource monitoring. Springer, Berlin

Drake JM, Bossenbroek JM (2004) The potential distribution of zebra mussels (Dreissena polymorpha) in the USA. Bioscience 54(10):931-941

Eckerson WW (2010) Performance dashboards: measuring, monitoring, and managing your business. Wiley, Hoboken

Executive Office of the President (1999) Executive Order 13112, 64 FR 6183-6186, 3 February 1999

Executive Office of the President (2016) Executive Order 13751, 81 FR 88609-88614, 5 December 2016

Ezell BC, Winterfeldt DV (2009) Probabilistic risk analysis and bioterrorism risk. Biosecur Bioterror 7(1):108-110

Fancy SG, Gross JE, Carter SL (2009) Monitoring the condition of natural resources in US national parks. Environ Monit Assess 151(1-4):161-174

Haack RA, Britton KO, Brockerhoff EG, Cavey JF, Garrett LJ et al (2014) Effectiveness of the international phytosanitary standard ISPM No. 15 on reducing wood borer infestation rates in wood packaging material entering the United States. PLoS ONE 9(5):e96611. https://doi.org/10.1371/ journal.pone.0096611

Hoffman JC, Schloesser J, Trebitz AS, Peterson GS, Gutsch M et al (2016) Sampling design for early detection of aquatic invasive species in Great Lakes ports. Fish 41(1):26-37

Hulme PE (2009) Trade, transport and trouble: managing invasive species pathways in an era of globalization. J Appl Ecol 46(1):10-18

Jachowski DS, Dobony CA, Coleman LS, Ford WM, Britzke ER, Rodrigue JL (2014) Disease and community structure: white-nose syndrome alters spatial and temporal niche partitioning in sympatric bat species. Divers Distrib 20(9):1002-1015

Jarrad F, Low-Choy S, Mengersen K (2015) Biosecurity surveillance: quantitative approaches (No. 6). Centre for Agriculture and Bioscience International, Boston, MA

Kamenova S, Bartley TJ, Bohan D, Boutain JR, Colautti RI et al (2017) Invasions toolkit: current methods for tracking the spread and impact of invasive species. Adv Ecol Invasions. https://doi.org/10.1016/bs.aecr.2016.10.009
Khamukhin AA, Bertoldo S (2016) Spectral analysis of forest fire noise for early detection using wireless sensor networks. In: 2016 international Siberian conference on control and communications (SIBCON), pp 1-4

Kunjan K, Doebbeling B, Toscos T (2018) Dashboards to support operational decision making in health centers: a case for role-specific design. Int J Hum Comput Interact. https:// doi.org/10.1080/10447318.2018.1488418

Leung B, Lodge DM, Finnoff D, Shogren JF, Lewis MA, Lamberti G (2002) An ounce of prevention or a pound of cure: bioeconomic risk analysis of invasive species. Proc $\mathrm{R}$ Soc Lond B Biol Sci 269(1508):2407-2413

Lindenmayer DB, Likens GE, Krebs CJ, Hobbs RJ (2010) Improved probability of detection of ecological "surprises". Proc Natl Acad Sci 107(51):21957-21962

Lodge DM, Williams S, MacIsaac HJ, Hayes KR, Leung B, Reichard S, Carlton JT (2006) Biological invasions: recommendations for US policy and management. Ecol Appl 16(6):2035-2054

Martinez B, Reaser JK, Dehgan A, Zamft B, Baisch D, McCormick C, Giordano AJ, Aicher R, Selbe S (2019) Technology innovation: advancing capacities for the early detection of and rapid response to invasive species. Biol Invasions. https://doi.org/10.1007/s10530-019-02146-y

McNeely JA, Mooney HA, Neville LE, Schei P, Waage JK (eds) (2001) A global strategy on invasive alien species. International Union for Conservation of Nature Gland, Switzerland

Meyers NM, Reaser JK, Hoff MH (2019) Instituting a national early detection and rapid response program: needs for building federal risk screening capacity. Biol Invasions. https://doi.org/10.1007/s10530-019-02144-0

Morrisseau S, Voyer C (2014) Tackling invasive species using citizen science. Green Teach 102:15-172019

National Invasive Species Council (2016) 2016-2018 National Invasive Species Council Management Plan. Washington, DC

Reaser JK, Brantley KA, Kirkey J, Burgiel SW, Veatch SD, Rodríguez-Burgos J (2019a) The early detection of and rapid response (EDRR) to invasive species: a conceptual framework and federal capacities assessment. Biol Invasions. https://doi.org/10.1007/s10530-019-02140-4

Reaser JK, Frey M, Meyers NM (2019b) Invasive species watch lists: guidance for development, communication, and application. Biol Invasions. https://doi.org/10.1007/ s10530-019-02143-1

Reaser JK, Guala GF, Simpson A, Morisette JA, Fuller P (2019c) Envisioning a national invasive species information framework. Biol Invasions. https://doi.org/10.1007/ s10530-019-02141-3

Régnière J, Nealis V (2002) Modelling seasonality of gypsy moth, Lymantria dispar (Lepidoptera: Lymantriidae), to evaluate probability of its persistence in novel environments. Can Entomol 134(6):805-824

Rodhouse TJ, Ormsbee PC, Irvine KM, Vierling LA, Szewczak JM, Vierling KT (2012) Assessing the status and trend of bat populations across broad geographic regions with dynamic distribution models. Ecol Appl 22(4):1098-1113

Roy HE, Adriaens T, Isaac NJ, Kenis M, Onkelinx T, Martin GS et al (2012) Invasive alien predator causes rapid declines of native European ladybirds. Divers Distrib 18(7):717-725 
Roy HE, van der Velde G, Zenetos A (2015) Invasive alien species: prioritising prevention efforts through horizon scanning. ENV.B.2/ETU/2014/0016. https://doi.org/10. 2779/096586

Russell JC, Binnie HR, Oh J, Anderson DP, Samaniego-Herrera A (2017) Optimizing confirmation of invasive species eradication with rapid eradication assessment. J Appl Ecol 54(1):160-169

Schroeder W, Oliva P, Giglio L, Quayle B, Lorenz E, Morelli F (2016) Active fire detection using Landsat-8/OLI data. Remote Sens Environ 185:210-220

Security and Accountability for Every Port Act (SAFE Port Act), Pub L. No. 109-347 (2006)

Sheehan KA (1992) User's guide for GMPHEN: gypsy moth phenology model. General Technical Report. US Department of Agriculture, Forest Service, Northeastern Forest Experiment Station, Newtown Square, PA

Stohlgren TJ, Schnase JL (2006) Risk analysis for biological hazards: what we need to know about invasive species. Risk Anal 26(1):163-173

Sutherland WJ, Woodroof HJ (2009) The need for environmental horizon scanning. Trends Ecol Evol 24(10):523-527

Taleb NN (2007) The black swan: the impact of the highly improbable, vol 2. Random House, New York

Tulloch AI, Possingham HP, Joseph LN, Szabo J, Martin TG (2013) Realising the full potential of citizen science monitoring programs. Biol Conserv 165:128-138

US Department of Agriculture (USDA) (2011) Agricultural Quarantine Inspection Monitoring (AQIM) Handbook, https://www.aphis.usda.gov/import_export/plants/ manuals/ports/downloads/aqim_handbook.pdf. Accessed 18 Aug 2018

US Department of Agriculture (USDA) (2014) 2014-2015 European gypsy moth risk assessment: project description and communication plan. APHIS-PPQ-Center for Plant Health Science and Technology, Fort Collins

US Department of Agriculture (USDA) (2018) Animal disease traceability. https:/www.aphis.usda.gov/aphis/ourfocus/ animalhealth/traceability. Accessed 22 Aug 2018

US Department of Homeland Security (DHS) and USDA (2003) Memorandum of Agreement Between the United States Department of Homeland Security and the United States Department of Agriculture. Agreement Numbers BTS-030001 (DHS) and 03-1001-0382-MU (USDA-APHIS) Washington, DC

US Forest Service (n.d.) Invasive species risk assessment: invasive species sample design tool. https://www.fs.fed.us/ foresthealth/applied-sciences/mapping-reporting/invasivespecies-risk/invasives-sample-design-tool.shtml. Accessed 5 Sept 2018

Wang O, Zachmann LJ, Sesnie SE, Olsson AD, Dickson BG (2014) An iterative and targeted sampling design informed by habitat suitability models for detecting focal plant species over extensive areas. PLoS ONE 9(7):e101196

Watters JK, Biernacki P (1989) Targeted sampling: options for the study of hidden populations. Soc Probl 36(4):416-430

Waugh JD (2009) Neighborhood watch: early detection and rapid response to biological invasion along US trade pathways. International Union for Conservation of Nature, Gland

Wong WH, Gerstenberger SL (2015) Biology and management of invasive quagga and zebra mussels in the western United States. CRC Press, Boca Raton

Publisher's Note Springer Nature remains neutral with regard to jurisdictional claims in published maps and institutional affiliations. 